Supporting Information

Impact of raw and bioaugmented olive mill wastewater and olive mill solid waste on the content of photosynthetic molecules in tobacco plants

Luigi Parrotta ${ }^{1}$, Tommaso Campani ${ }^{2}$, Silvia Casini ${ }^{2}$, Marco Romi ${ }^{1}$, Giampiero Cai* $^{1}$

${ }^{1}$ Dipartimento Scienze Biologiche, Geologiche e Ambientali, Università di Bologna, via Irnerio 42, 40126 Bologna (Italy)

${ }^{2}$ Dipartimento Scienze Fisiche, Territorio e Ambiente, Università di Siena, via Mattioli 4, 53100 Siena (Italy)

3 Dipartimento Scienze della Vita, Università di Siena, via Mattioli 4, 53100 Siena (Italy)

Corresponding author's e-mail address: giampiero.cai@unisi.it

\section{A (OMWW)}
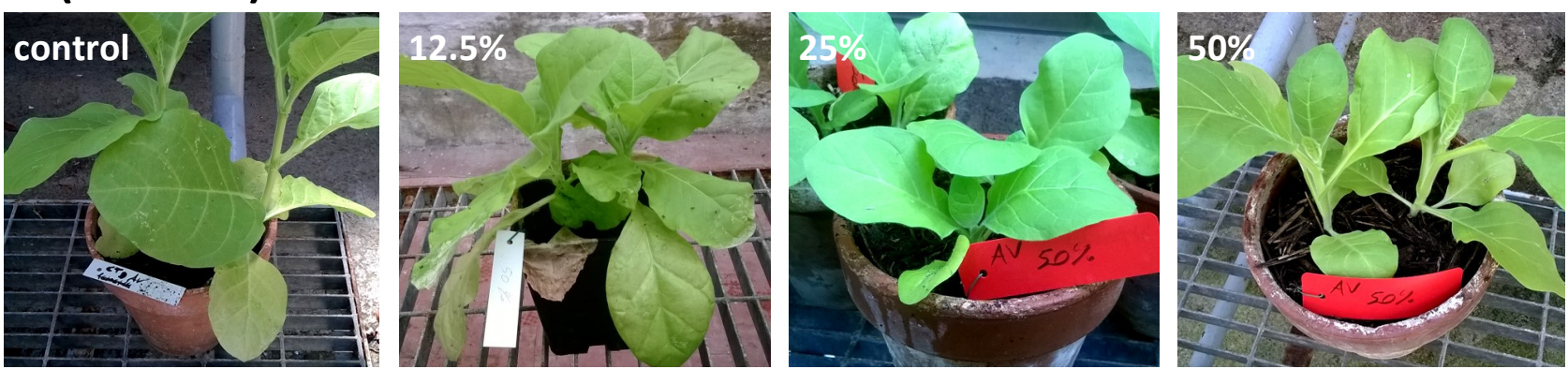

\section{B (OMSW)}
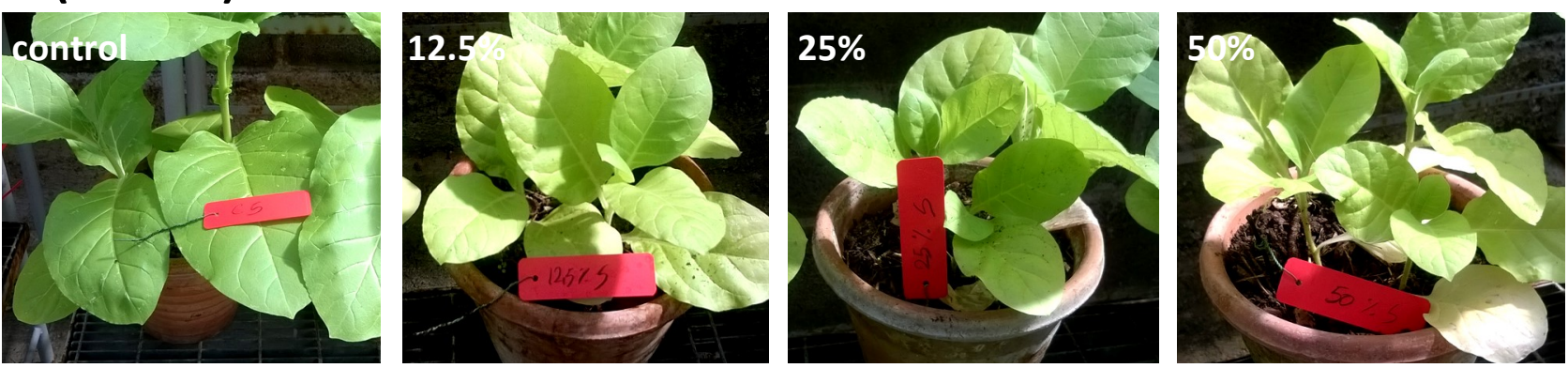

Figure S1. Tobacco plants grown in the presence of either OMWW or OMSW at different percentages. No morphological alteration is evident regardless of the concentration of treatment . 